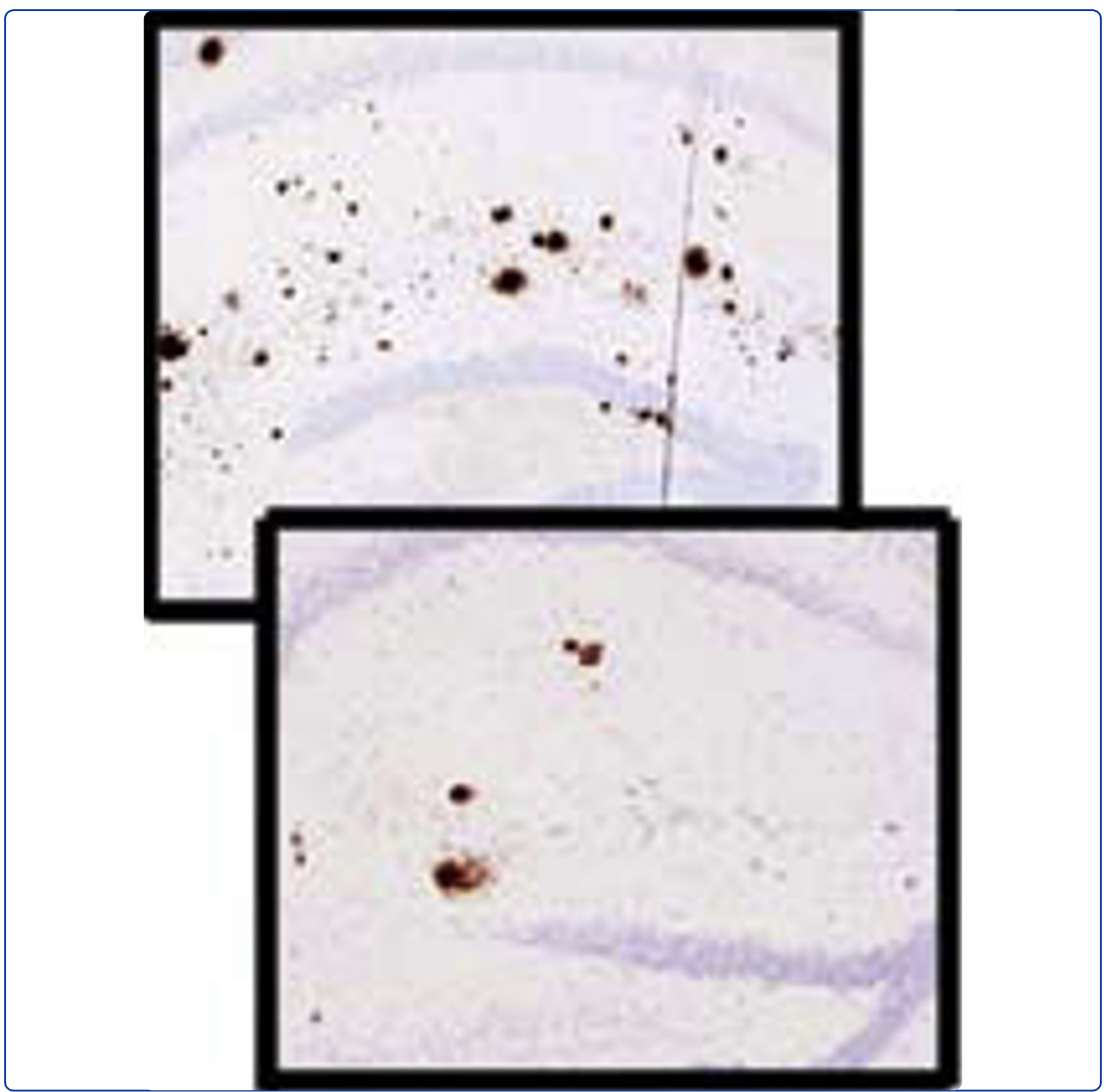

\title{
Hippocampal expression of murine TNFa results in attenuation of amyloid deposition in vivo
}

Chakrabarty et al. 


\title{
Hippocampal expression of murine TNF $\alpha$ results in attenuation of amyloid deposition in vivo
}

\author{
Paramita Chakrabarty ${ }^{1}$, Amanda Herring ${ }^{2}$, Carolina Ceballos-Diaz' ${ }^{1}$ Pritam Das ${ }^{2}$, Todd E Golde ${ }^{1^{*}}$
}

\begin{abstract}
Fibrillar amyloid $\beta$ (fA $\beta$ ) peptide is the major component of $A \beta$ plaques in the brains of Alzheimer's disease (AD) patients. Inflammatory mediators have previously been proposed to be drivers of A $\beta$ pathology in AD patients by increasing amyloidogenic processing of APP and promoting A $\beta$ accumulation, but recent data have shown that expression of various inflammatory cytokines attenuates $A \beta$ pathology in mouse models. In an effort to further study the role of different inflammatory cytokines on $A \beta$ pathology in vivo, we explored the effect of murine Tumor Necrosis Factor $\alpha$ (mTNF $\alpha$ ) in regulating A $\beta$ accumulation. Recombinant adeno-associated virus serotype 1 (AAV2/1) mediated expression of mTNF $\alpha$ in the hippocampus of 4 month old APP transgenic TgCRND8 mice resulted in significant reduction in hippocampal A $\beta$ burden. No changes in APP levels or APP processing were observed in either mTNF $\alpha$ expressing APP transgenic mice or in non-transgenic littermates. Analysis of A $\beta$ plaque burden in mTNF $\alpha$ expressing mice showed that even after substantial reduction compared to EGFP expressing age-matched controls, the $A \beta$ plaque burden levels of the former do not decrease to the levels of 4 month old unmanipulated mice. Taken together, our data suggests that proinflammatory cytokine expression induced robust glial activation can attenuate plaque deposition. Whether such an enhanced microglial response actually clears preexisting deposits without causing bystander neurotoxicity remains an open question.
\end{abstract}

\section{Findings}

Amyloid $\beta(A \beta)$ plaques are a hallmark pathological feature of Alzheimer's disease (AD). Neuroinflammation, characterized by $\mathrm{A} \beta$ plaque associated reactive gliosis and increased levels of pro-inflammatory cytokines, has been hypothesized to lead to exacerbated $\mathrm{AD}$ pathology [1]. However, recent data has shown that activated glia [2-4] and myeloid lineage cells [5-8] ameliorate brain $\mathrm{A} \beta$ plaque load in $\mathrm{A} \beta$ precursor protein (APP) transgenic mouse models. We have previously demonstrated that increased expression of murine Interleukin-6 (IL-6) or murine Interferon- $\gamma($ IFN $\gamma$ ) results in attenuation of A $\beta$ deposition in APP transgenic mice via synergistic activation of glia and innate immune system components $[2,3]$. In our effort to further analyze the role of different inflammatory cytokines on $A \beta$ pathology, we investigated the effect of murine tumor necrosis factor $\alpha(\mathrm{mTNF} \alpha)$ expression in APP transgenic mice. TNF $\alpha$

\footnotetext{
* Correspondence: tgolde@mbi.ufl.edu

${ }^{1}$ Center for Translational Research in Neurodegenerative Disease, College of Medicine, University of Florida, 1275 Center Drive, Gainesville, PO Box \#100159, FL-32610, USA

Full list of author information is available at the end of the article
}

is an inflammatory cytokine produced by macrophages, lymphoid cells, endothelial cells [9], neurons [10] and glia [11]. Various functional as well as genetic association studies have implicated increased levels of TNF $\alpha$ in exacerbating AD pathology [12]. Levels of TNF $\alpha$ and that of its receptors, TNF-RI and TNF-RII, are elevated in $\mathrm{AD}$ patients [13-15]. Though initial studies implicated three TNF $\alpha$ polymorphisms with increased AD [16], a subsequent study showed that these same polymorphisms delay the age of $\mathrm{AD}$ onset [17]. In preclinical mouse models, deletion of the TNF-RI gene or expression of the dominant negative truncated receptor reduces $A \beta$ plaque formation in APP transgenic mice, suggesting a direct role in APP processing $[18,19]$. Studies in the $3 \times$ Tg-AD mouse model expressing mutant APP, tau and presenilin showed that there was agerelated increase in TNF $\alpha$ levels [20] and neuronal expression of TNF $\alpha$ exacerbated $A \beta$ and tau pathology in these mice [21].

To investigate the role of $m \mathrm{TNF} \alpha$ in regulating $A \beta$ accumulation in the CNS, we used recombinant adenoassociated virus (rAAV) to express mTNFa in the hippocampus of APP transgenic TgCRND8 mice [22].
C Biomed Central

(c) 2011 Chakrabarty et al; licensee BioMed Central Ltd. This is an Open Access article distributed under the terms of the Creative Commons Attribution License (http://creativecommons.org/licenses/by/2.0), which permits unrestricted use, distribution, and reproduction in any medium, provided the original work is properly cited. 
Recombinant AAV2 plasmids containing mTNF $\alpha$ (Open Biosystems, clone 40126376) or enhanced green fluorescent protein (EGFP) under the control of the cytomegalovirus enhancer/chicken $\beta$ actin promoter were packaged in AAV serotype 1 capsid (rAAV2/1) as described previously $[2,23]$. Adult 4 month old TgCRND8 mice were stereotaxically injected into the hippocampus (interaural coordinates, anteroposterior:-2.2, mediolateral:+/-1.6, dorsoventral: -1.2$)$ with $2 \mu \mathrm{l}$ of AAV2/1 constructs $(1 \times$ $10^{13}$ particles $/ \mathrm{ml}$ ) and then sacrificed for analysis at 5.5 months $(n=5$ for $\mathrm{rAAV} 2 / 1-\mathrm{mTNF} \alpha ; n=6$ for rAAV2/1-EGFP). The procedures were approved by the IACUC and performed as described previously [2]. In previous studies we have found that AAV2/1-EGFP expression has no effect on amyloid pathology or gliosis when compared to uninjected mice [2,23]; so, AAV2/1EGFP injected mice were used as the control cohort. Following euthanasia, the mice brains were coronally dissected $1 \mathrm{~mm}$ anterior and $1 \mathrm{~mm}$ posterior to the point of injection and used for subsequent analysis. Anti-EGFP immunohistochemistry (Invitrogen, 1:1000) on paraffin embedded brain sections of AAV2/1-EGFP injected mice showed that the viral transgene is predominantly expressed in the hippocampal CA neurons, parts of the dentate gyrus, neuronal projections in the cortex and some overlying cortical neurons 6 week post-injection (Additional File 1, Fig S1, A-D). Reverse transcribed (Superscript III; Invitrogen) total RNA from mice brain was amplified using primer sequences from the Roche Universal Probe Library (Roche). Quantitative PCR analysis of transcripts showed that there were increased levels of mTNFa (Additional File 1, Fig S1, E) in the hippocampus of AAV2/1-mTNFa expressing mice compared to EGFP expressing controls. Immunohistochemical analysis performed on paraffin embedded mouse brain sections showed widespread GFAP positive astrocytes (antiGFAP, Sigma, 1:1000; Figure 1A-D) as well as Iba-1 positive microglia (anti-Iba-1, Wako; 1:1000; Figure 1E-H) in the hippocampus of mTNF $\alpha$ expressing mice. Quantification of immunostaining using the "positive pixel count" program (Aperio, Vista, CA) showed significant increases ( $p=0.05 ; t$ test) in both astrocytic staining (2.58 fold
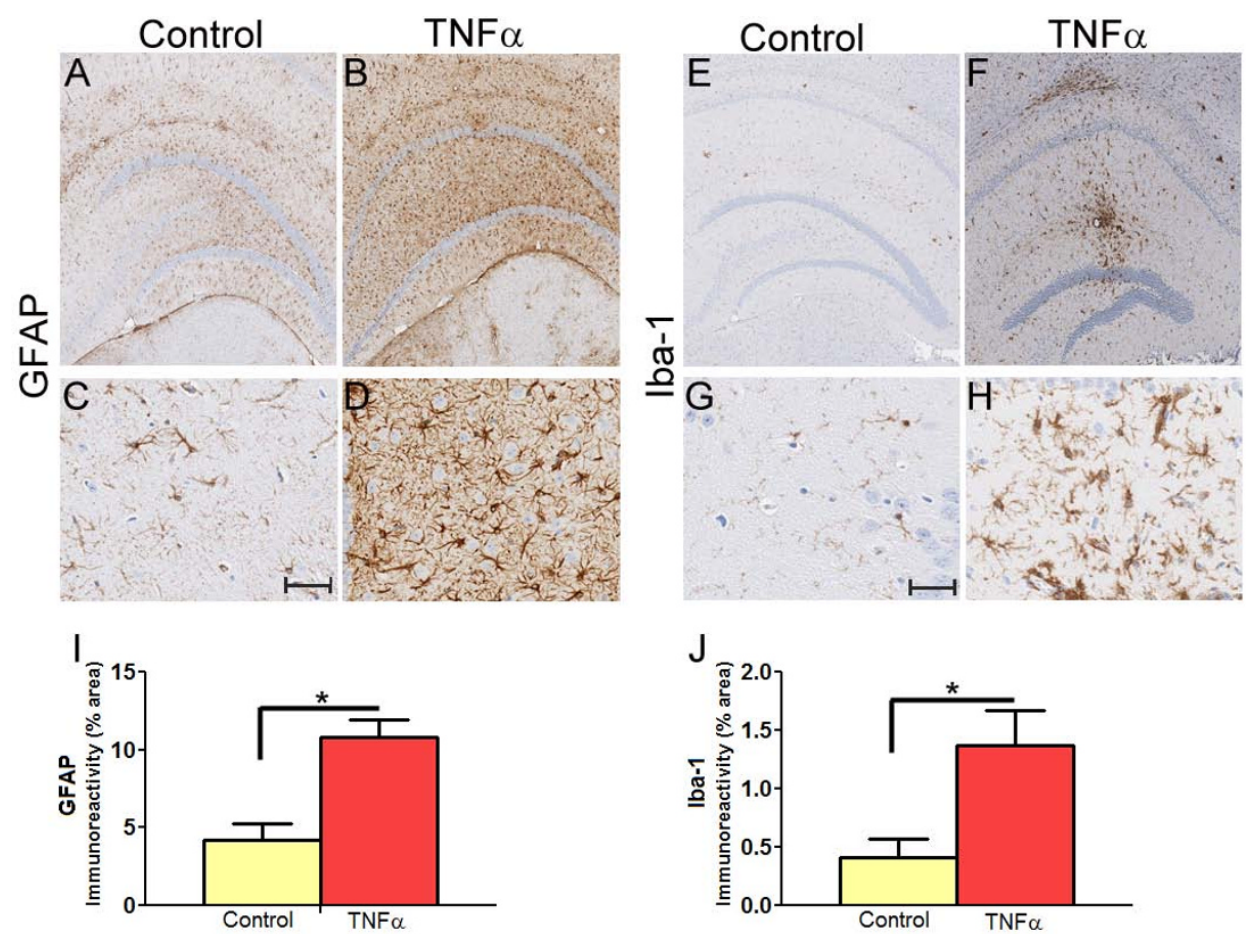

Figure 1 AAV2/1 mediated expression of mTNF $\alpha$ in the hippocampus of TgCRND8 mice leads to robust neuroinflammation. A-D rAAV2/1-mTNF $\alpha$ or rAAV2/1-EGFP (Control) was injected into the hippocampus of 4 month old TgCRND8 mice and analyzed after 6 weeks. Representative images of GFAP immunoreactivity in paraffin embedded whole brain sections (A, B) and higher magnification of the hippocampus (C, D) of 5.5 month old TgCRND8 mice are shown. Scale Bar, $600 \mu \mathrm{m}$ (A, B) and $25 \mu \mathrm{m}(\mathrm{C}, \mathrm{D})$. ( $\mathrm{n}=5 / \mathrm{group})$. E-H. Representative images of Iba-1 immunoreactivity in paraffin embedded sections of 5.5 month old TgCRND8 mice injected with rAAV2/1 mTNF $\alpha$ or rAAV2/1EGFP (Control). Whole brain sections ( $E, F)$ and the corresponding hippocampus $(G, H)$ showing detailed morphology of the activated microglia is depicted. Scale Bar, $600 \mu \mathrm{m}(\mathrm{E}, \mathrm{F})$ and $25 \mu \mathrm{m}(\mathrm{G}, \mathrm{H})$. (n = 5/group). I-J. Quantitation of GFAP (I) and Iba-1 (J) immunoreactivity burden (\% area) in paraffin embedded sections of TgCRND8 mice expressing mTNF $\alpha$ or EGFP as control. The "positive pixel count" program available from Aperio was used for the analysis. ( ${ }^{*} p<0.05 ; t$ test; $n=5 /$ group). 
increase in GFAP burden; Figure 1I) and microglial staining (3.36 fold increase in Iba-1 burden; Figure 1J). Activated microglial immunoreactivity was especially robust along the projected path of stereotaxic injection (Figure 1F, H). Since TNF $\alpha$ has been shown to cause neuronal apoptosis [24], we performed hippocampal cell counts on paraffin embedded mouse brain sections using the "Nuclear Quantification" program (Aperio). Data from ten representative hippocampal CA areas $(1000 \mu \mathrm{m}$ $\times 60 \mu \mathrm{m})$ from each of three sections per sample $(30 \mu \mathrm{m}$ apart) were averaged for the final output ( $n=4$ /group). No significant differences were found ( $p=0.45$, unpaired $t$ test) in the number of hippocampal CA cells in the two mice groups (Additional File 2, Fig S2).

A $\beta$ plaque burden in mice brain was quantified by immunohistochemistry with pan $\mathrm{A} \beta$ antibody 33.1.1 (1:1500, human $A \beta 1-16$ specific), $A \beta 42$ antibody 2.1 .3
(1:1000; human $A \beta 42$ specific) and $A \beta 40$ antibody 13.1 .1 (1:1000; human $A \beta 40$ specific) [23]. Using the positive pixel count program (Aperio), the plaque burden (\% area) was calculated by averaging the data obtained from three sections, $30 \mu \mathrm{m}$ apart, per sample ( $\mathrm{n}=5-6 /$ group). We observed a $36 \%(p=0.033 ; t$ test $)$ decrease in total $\mathrm{A} \beta$ plaque burden within the dissected coronal section in the mTNF $\alpha$ expressing mice compared to EGFP injected mice (Figure 2A-E). A small $(10 \% ; p=0.05 ; t$ test) but statistically significant decrease in compact congophilic plaques was seen in the hippocampus of the mTNF $\alpha$ expressing mice compared to controls (Figure 2F). Biochemical levels of $A \beta$ was measured following serial extraction of mouse hippocampus with RIPA buffer (Boston Biological), 2\% SDS and $70 \%$ formic acid (FA) ( $n=5-6 /$ group). A significant reduction in SDS extractable A $\beta 42(59 \%, \mathrm{p}<0.05$, two

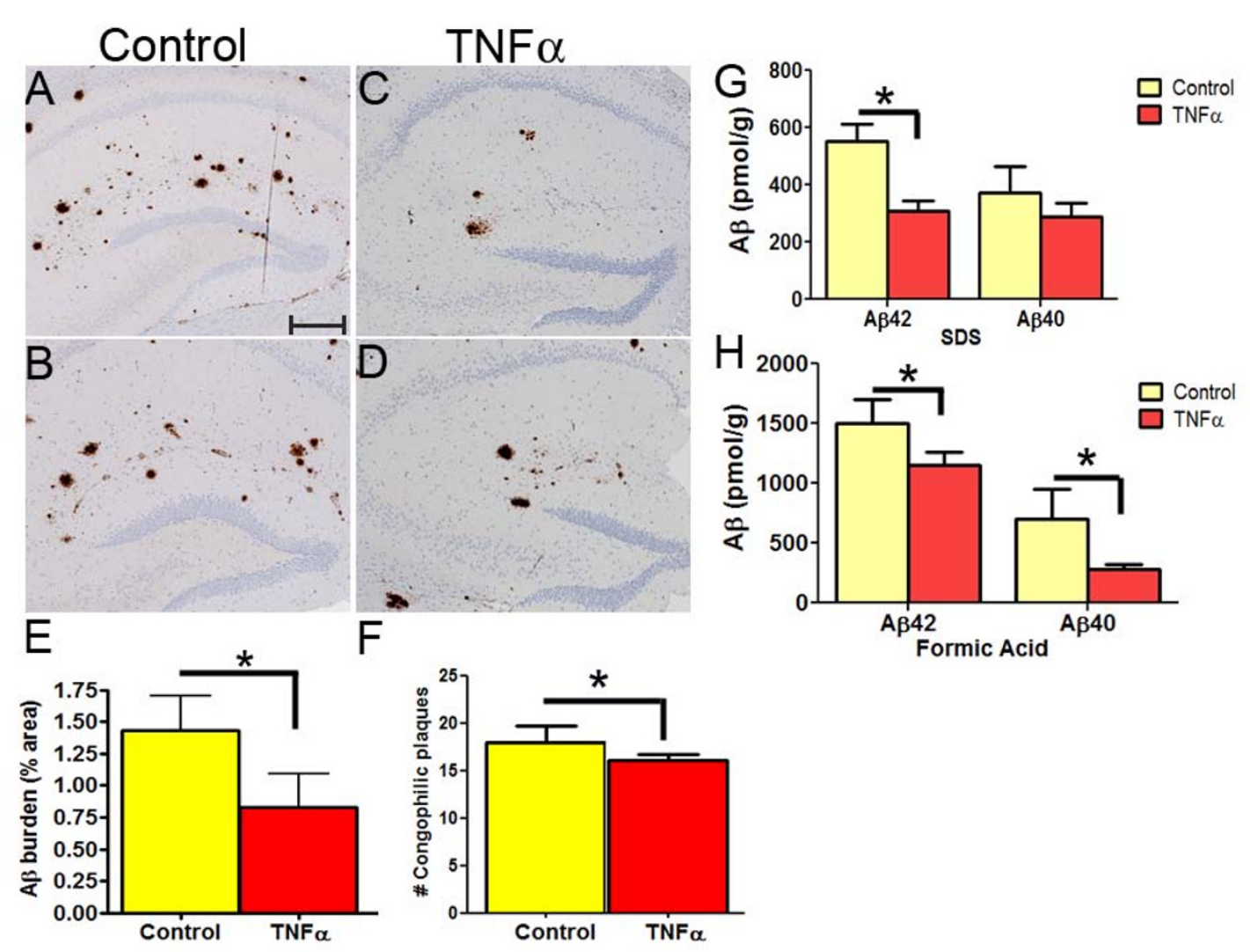

Figure 2 Reduction of hippocampal A $\beta$ in AAV2/1-mTNF $\alpha$ expressing TgCRND8 mice. A-D. 4 month old TgCRND8 mice were stereotaxically injected in the hippocampus with either AAV2/1-mTNF $\alpha$ or AAV2/1-EGFP and sacrificed after 6 weeks ( $n=5-6 / \mathrm{group})$. Representative brain sections stained with 33.1.1 antibody (pan A 1 1-16) depict attenuation of A $\beta$ deposition in mTNF $\alpha$ expressing mice (C-D) compared to controls (A-B) in the immediate vicinity of the injection site. Scale Bar, $150 \mu \mathrm{m}$. E. A $\beta$ plaque burden image analysis shows a significant decrease in amyloid deposition in MTNF $\alpha$ injected mice compared to control EGFP injected mice. At least three sections per sample, spaced $30 \mu \mathrm{m}$ apart, were used for the analysis. ( ${ }^{*} p=0.033 ; t$ test; $n=5 /$ group). F. Quantitation of Congo Red stained compact A $\beta$ plaques in mTNF $\alpha$ injected mice compared to control EGFP injected mice. Hippocampal compact plaques were counted from coronally dissected paraffin embedded representative brain sections of mTNF $\alpha$ and EGFP expressing mice. ( ${ }^{*} p=0.05 ; t$ test; $n=5 /$ group). G-H. Biochemical analyses of A 42 and A 40 levels by ELISA show significantly reduced SDS (G) and formic acid (H) extractable A levels in mTNF $\alpha$ injected mice compared to controls ( ${ }^{*} p=0.05 ;$ two way ANOVA; $n=4 /$ group). 
way ANOVA) and a non-significant 23\% reduction in A $\beta 40$ levels in the mTNF $\alpha$ expressing mice compared with age-matched EGFP-expressing controls was noted (Figure 2G). Similarly, the FA fractions showed a 23\% reduction in $\mathrm{A} \beta 42(p<0.05$; two way ANOVA) and a $43 \%$ reduction in $\mathrm{A} \beta 40$ levels $(p<0.05$; two way ANOVA) in rAAV2/1-mTNF $\alpha$ expressing mice compared to controls (Figure 2H). Janelsins et al [21] have reported increased intracellular $\mathrm{A} \beta$ following hippocampal expression of AAV-human TNFa in $3 \times \mathrm{Tg}$-AD mice; although following long-term expression, there was decreased extracellular $A \beta$ plaque deposition, which the authors attributed to neuronal loss. Though we have noticed sparse punctuate intracellular $A \beta$ immunorectivity in CRND8 mice, primarily in a subset of neurons within the subiculum, such intracellular $A \beta$ immunoreactivity was not notably altered by mTNF $\alpha$ (data not shown). The differences in our current observations may be due to the differences in transgenic mouse models and timing of experimental endpoints.

To probe whether the decrease in $A \beta$ is the result of an active clearance process or a result of inhibition of deposition, we compared the extent of reduction of $A \beta$ levels in mTNF $\alpha$ expressing mice to the $A \beta$ levels in the original starting point of the study by analyzing the plaque burdens of 5.5 month old mTNF $\alpha$ expressing mice, 5.5 month old EGFP expressing mice (age-matched control) and 4 month old unmanipulated mice. We quantified both the "cored" A $\beta$ plaque burden (indicated by A $\beta 40$ specific 13.1.1 immunostaining; Figure $3 D-F)$ and "total" $A \beta$ plaque burden (indicated by $A \beta 42$ specific 2.1.3 immunostaining; Figure 3A-C) in the hippocampus of 5.5 month old TgCRND8 mice and compared them to unmanipulated 4 month old TgCRND8 mice $(n=5 /$ group). There were reductions in $\mathrm{A} \beta 42$ and $\mathrm{A} \beta 40$ plaque burden in the mTNF $\alpha$ expressing mice compared with age-matched EGFP-expressing controls $(56 \%, p<$ 0.05 , two way ANOVA, and $35 \%, \mathrm{p}>0.1$; two way ANOVA, decrease respectively) (Figure 3G). However, both the $A \beta 42$ and the $A \beta 40$ plaque burdens of the unmanipulated 4 month old group was lower than the mTNF $\alpha$-expressing mice, by $25 \%$ ( $p>0.1$; two way ANOVA) and $42 \%$ ( $p<0.05$; two way ANOVA) respectively (Figure $3 G$ ). The larger decrease in $A \beta 42$ plaque burden, which measures both diffuse and cored plaque with a relatively smaller decrease in the $A \beta 40$ "cored" plaque burden, suggests that mTNF $\alpha$ has preferential effects on more diffuse plaques.

To determine whether mTNF $\alpha$ alters APP levels or APP processing, we performed immunoblotting using anti APP CT20 antibody (1:1000) [2] and 4G8 antibody (Chemicon; 1:1000) on RIPA extracted brain lysates (n $=3$ /group). No significant changes in APP levels (Figure $4 \mathrm{~A}-\mathrm{B})$ or APP $\mathrm{C}$ terminal fragments (CTF $\alpha$ and $\mathrm{CTF} \beta)$ between mTNF $\alpha$ and EGFP expressing TgCRND8 mice were detected (Figure 4A-D). Additionally, no significant changes were detected in endogenous APP protein levels ( $\mathrm{n}=4$ /group) in $\mathrm{mTNF} \alpha$ injected wild type B6C3 mice (non-transgenic littermates of TgCRND8 mice) compared to control age-matched EGFP expressing B6C3 mice (Figure 4E-F), signifying that mTNF $\alpha$ does not alter endogenous mouse APP expression through interaction with cellular transcriptional or post-transcriptional mechanisms. Since other pro-inflammatory cytokines, namely, Interleukin-6 [3] and Interferon $\gamma$ [2] also fail to cause upregulation in APP levels in vivo, the possible involvement of a pro-inflammatory cytokine induced amyloidogenic "cytokine cycle" [25] in AD pathology is debatable.

In the absence of changes in steady state APP levels, we investigated whether $m T N F \alpha$-induced $A \beta$ reduction results from enhanced activation of the innate immune system. To test for the presence of activated glia, we performed double-labeling immune-fluorescent staining using Texas Red conjugated Tomato Lectin (Vector Labs, 1:500) and 4G8 anti A $\beta$ antibody (1:1000; Chemicon). The intensity and clustering of tomato lectin staining in close apposition to $A \beta$ plaques was found to be increased in the hippocampus of $\mathrm{mTNF} \alpha$ expressing mice (Figure 5D-F) compared to age-matched EGFP expressing controls (Figure 5A-C). This is similar to our previous observations that enhanced glial association with plaques as well as phagocytic activity may contribute to reductions in A $\beta$ loads in APP transgenic mice $[2,4,8,26]$.

Previous studies have shown that TNF $\alpha$ expression in the brain results in T cells infiltrating the CNS [9] and that following $\mathrm{A} \beta$ immunization, $\mathrm{T}$ cells may play a role in $\mathrm{A} \beta$ removal [27]. However, no CD3 (Abcam; 1:100) immunopositive $\mathrm{T}$ cells were detected in close proximity to the $\mathrm{A} \beta$ plaques (Additional File 3, Fig S3, B), though the antibody recognized $T$ cells in paraffin embedded tonsil (Additional File 3, Fig S3, A). To investigate the glial subpopulations that effectively restrict plaque deposition, we performed MHC II (Abcam; 1:150) immunostaining on paraffin embedded brain sections followed by Congo Red and hematoxylin counterstaining ( $\mathrm{n}=5$ /group). At least 10 Congophilic plaques from the hippocampus of each sample were averaged for the final analysis. MHC class II, a classic marker of activated scavenger cells [28] was previously shown to be highly expressed among glia directly in contact with amyloid plaques, suggestive of increased phagocytic removal of $\mathrm{A} \beta$ [4]. A $56 \%(p<0.05, t$ test $)$ increase in the number of MHCII reactive cells associated with Congophilic plaques was seen in the hippocampus of mTNF $\alpha$ expressing mice compared to EGFP expressing mice (Figure 5G-K). Collectively, our data demonstrates that acute 

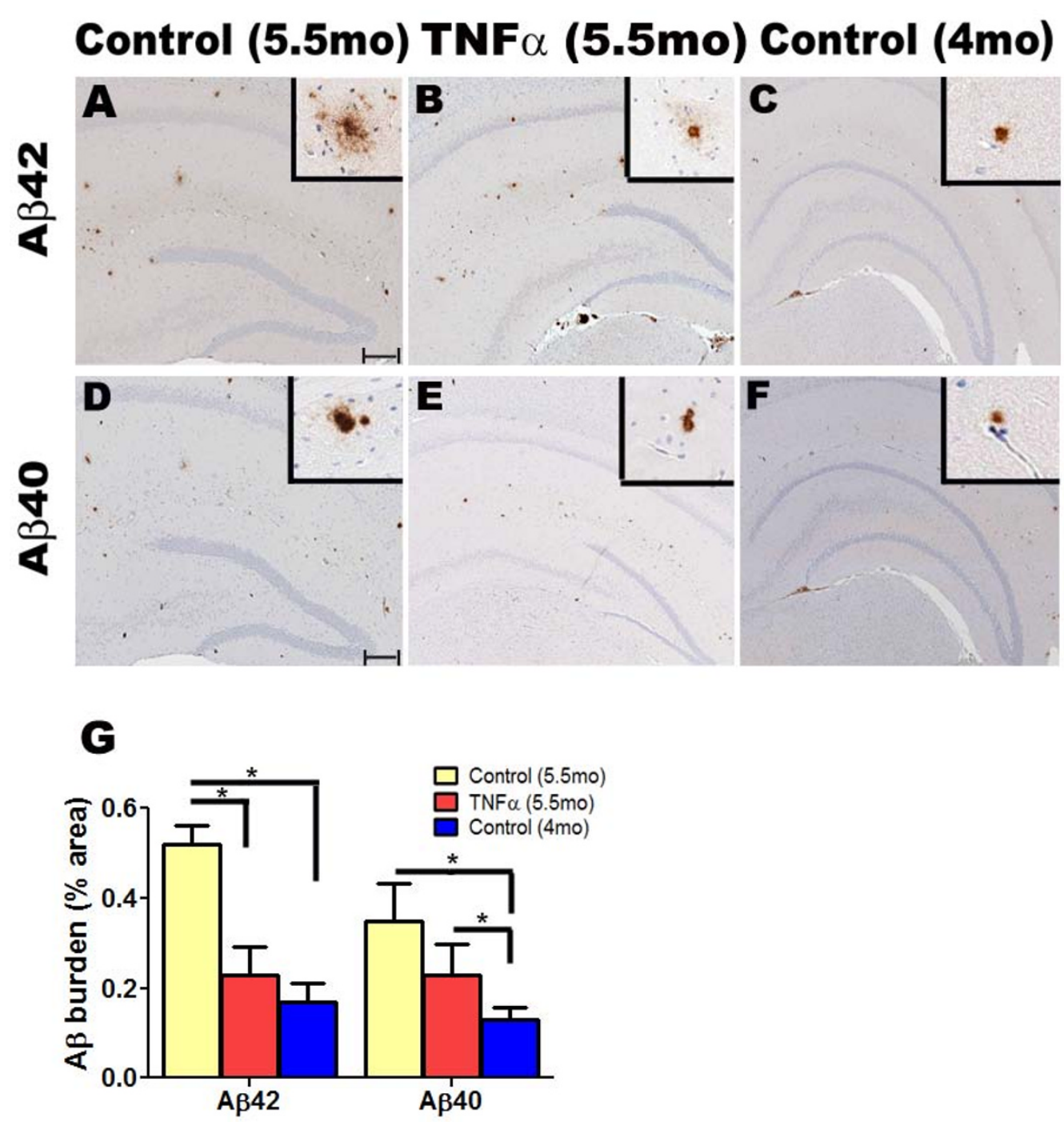

Figure 3 Analysis of $A \beta 42$ and $A \beta 40$ plaque burden reveals that acute focal expression of $m$ TNF $\alpha$ in the hippocampus of TgCRND8 mice results in attenuation of $\mathbf{A} \boldsymbol{\beta}$ deposition. A-F. 4 month old TgCRND8 mice were stereotaxically injected in the hippocampus with either rAAV2/1-mTNF $\alpha$ or rAAV2/1-EGFP and sacrificed after 6 weeks. Representative brain sections from EGFP and mTNF $\alpha$ expressing 5.5 month old mice as well as unmanipulated 4 month old mice were stained with anti $A \beta 42$ antibody $(A-C)$ and anti $A \beta 40$ antibody (D-F). Insets depict representative magnified field of views from corresponding low power panel. Scale Bar, $600 \mu \mathrm{m}$ (A-F); inset, $25 \mu \mathrm{m}$. ( $\mathrm{n}=5 / \mathrm{group})$. G. Hippocampal A $\beta 42$ and A 440 plaque burden analysis was performed in paraffin embedded brain sections of 5.5 month old mTNF $\alpha$ and EGFP expressing mice as well as unmanipulated 4 month old TgCRND8 mice. At least three sections per sample, spaced $30 \mu \mathrm{m}$ apart, were used for the analysis. The "Positive Pixel Count" program available from Aperio was used for the analysis. ( $p<0.05$; two way ANOVA; $n=5 / g r o u p)$.

expression of an inflammatory cytokine attenuates $A \beta$ pathology. Given that the common feature between IL$6, \mathrm{IFN}-\gamma$ and TNF $\alpha$ expression in the brains of APP mice is robust glial activation and absence of effects on APP processing, such data suggests that pro-inflammatory cytokine driven gliosis primarily prevents $A \beta$ deposition and/or enhances $A \beta$ aggregate removal.

A contentious issue in this study and other similar studies [2] is whether pre-existing plaque pathology can be altered by modulating glial activity. This issue has important implications with respect to defining temporal windows for therapeutic intervention. Comparative analysis of $\mathrm{A} \beta$ plaque burdens from our previous studies $[2,3]$ and the present study show that while there was a significant decrease in $A \beta$ plaque burden in the cytokine expressing adult APP transgenic mice compared to control cohorts, the levels did not decrease beyond that of unmanipulated 4 month old mice (Figure 6; $p=0.0011$, one way ANOVA). Thus, from our data, we can infer that following the expression of inflammatory cytokines 


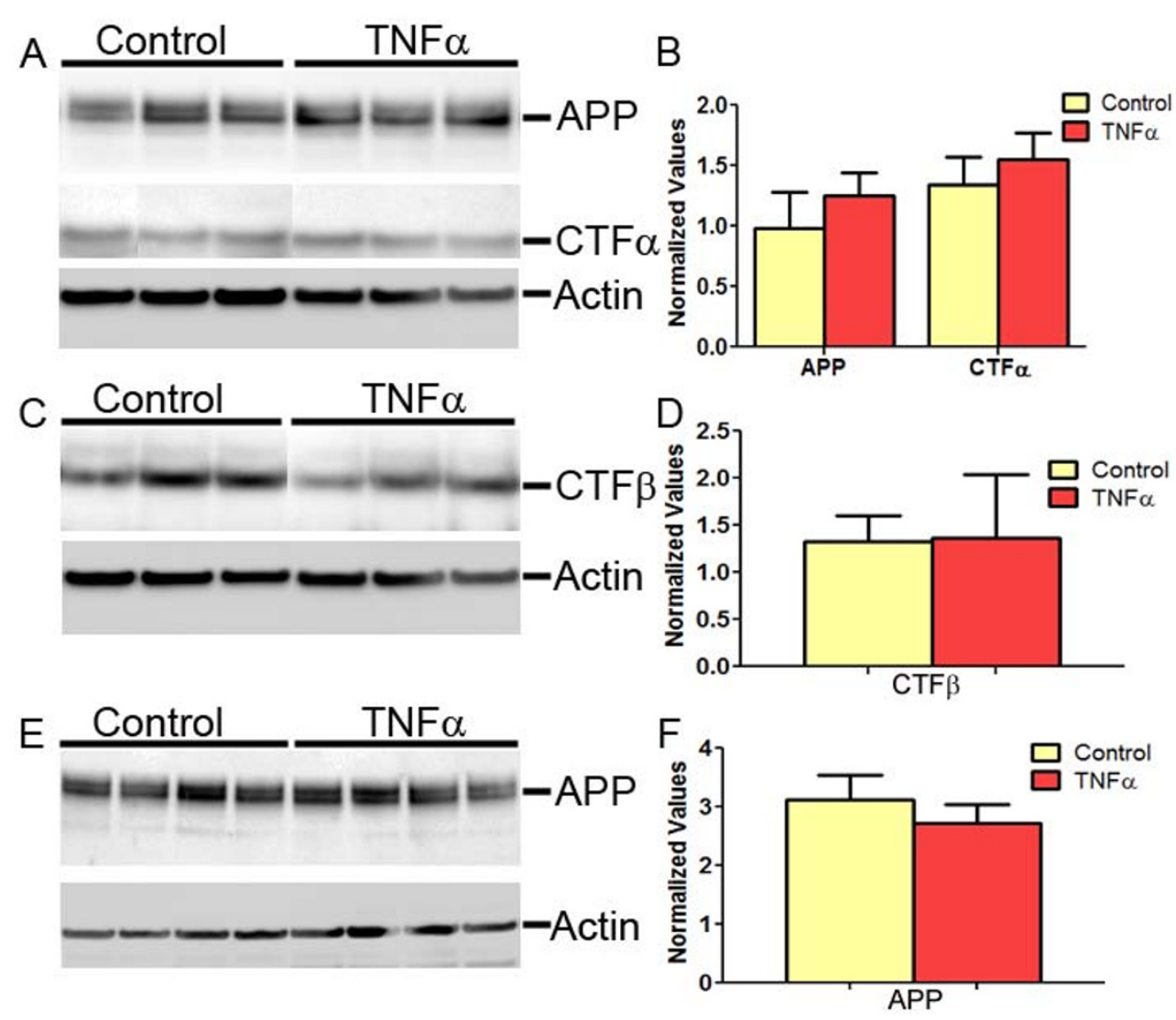

Figure 4 APP or APP CTF levels were not significantly altered in mTNF $\alpha$ expressing mice. A-B. Representative anti CT20 immunoblot showing no significant changes in APP or CTF $\alpha$ levels in AAV2/1-mTNF $\alpha$ expressing TgCRND8 compared to age-matched transgenic mice expressing EGFP (control cohort) (A). Intensity analysis of anti CT20 immunoreactive APP and CTF $\alpha$ levels was normalized to $\beta$-actin in TgCRND8 mice cohort (B). ( $n=3$ /group). C-D. Representative anti 4G8 immunoblot showing no significant changes in CTF $\beta$ levels in AAV2/1-mTNF $\alpha$ expressing TgCRND8 compared to age-matched transgenic mice expressing EGFP (control cohort) (C). Intensity analysis of anti 4G8 immunoreactive CTF $\beta$ levels was normalized to $\beta$-actin in TgCRND8 mice cohort (D). ( $n=3 /$ group). E-F. Representative anti CT20 immunoblot showing no significant changes in APP levels in AAV2/1-mTNF $\alpha$ expressing non transgenic B6C3 mice compared to age-matched non transgenic B6C3 expressing EGFP (E). Intensity analysis of anti CT20 immunoreactive APP levels was normalized to $\beta$-actin in the wild type mice cohort (F). ( $n=4$ /group).

in the brain and activation of innate immune system components, $\mathrm{A} \beta$ deposition is attenuated; however, whether active clearance may also be occurring concurrently is still debatable.

Using multiple paradigms, we and others [2-8] have demonstrated that proinflammatory cytokine mediated glial activation is associated with attenuation of CNS A $\beta$ deposition in APP mouse models and in some cases possibly result in actual clearance of pre-existing plaques $[29,30]$. We find no evidence for altered levels or processing of the human APP transgene or endogenous mouse APP suggesting that enhanced glial activation attenuates $A \beta$ accumulation most likely by altering $A \beta$ clearance. Of course, the use of a human APP cDNA transgene driven by a heterologous promoter in many of these models imposes some limitations on the final interpretation of these studies, as it is possible that translational and transcriptional control of the APP gene and mRNA, respectively, is different between mice and humans. A next step could be to use the APP YAC transgenic mice [31], but even in this case the differences in the transcriptional and translational machineries of humans and mice may confound the outcome.

In $\mathrm{AD}$ patients and in $\mathrm{AD}$ mouse models there is an inevitable age-progressive accrual of $A \beta$ aggregates despite widespread reactive gliosis. Thus, it appears that the normal reactive gliosis induced by $A \beta$ accumulation is insufficient to overcome the inexorable accumulation of aggregated $A \beta$. Some have suggested that microglial aging may lead to inefficient or abortive $A \beta$ phagocytosis [32,33], but such a hypothesis is difficult to reconcile with the observation that age of onset of $A \beta$ plaque pathology in both humans and mouse models mice can occur very early in life. An intriguing possibility is that 

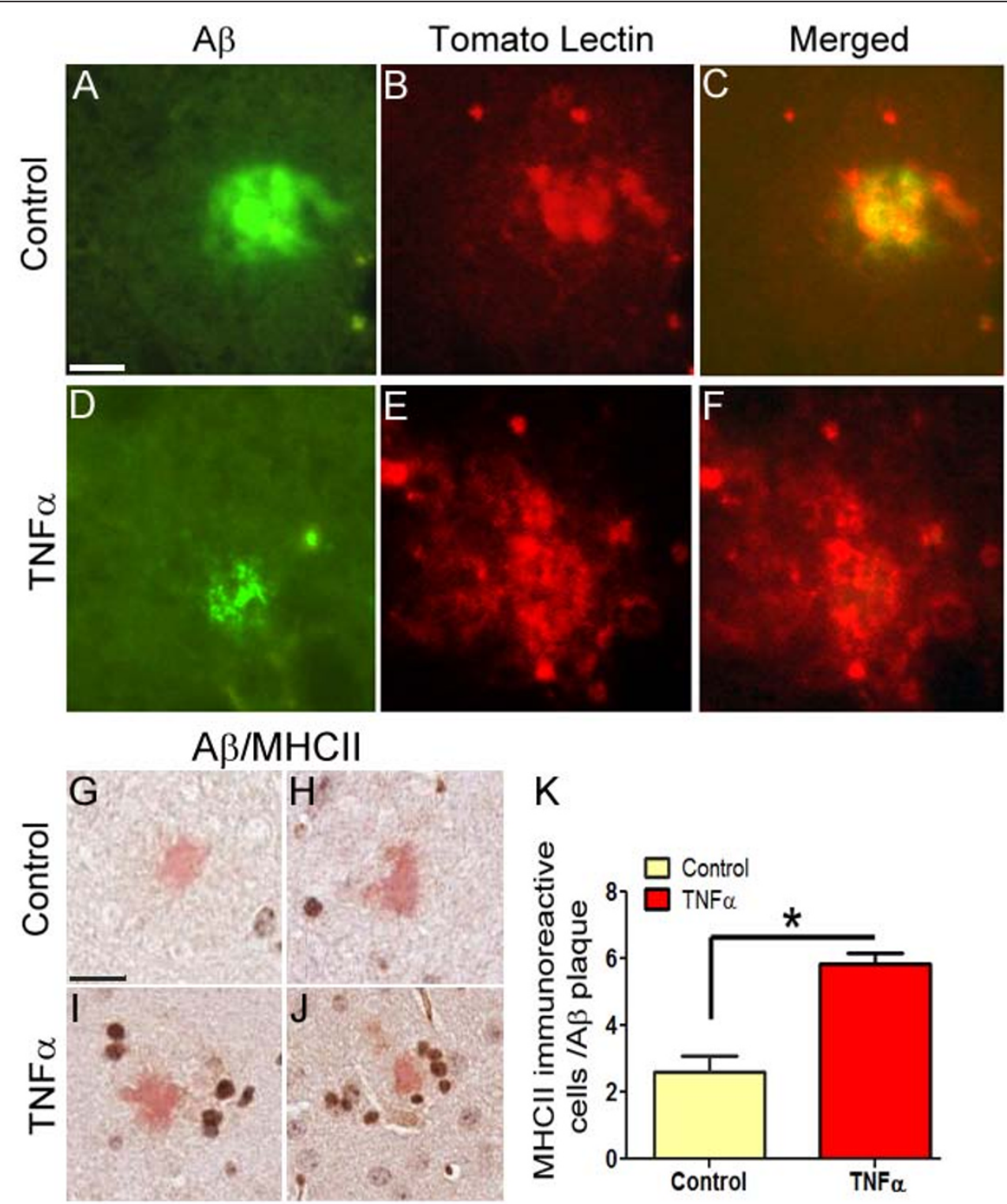

Figure 5 Increased levels of immune activation in mTNF $\alpha$ expressing TgCRND8 mice. A-F. Representative sections from the hippocampus of EGFP (A-C) or mTNF $\alpha$ expressing mice (D-F) from 5.5 month old TgCRND8 mice depicting increased clustering of tomato lectin binding activated glia (depicted in red) in close contact with $A \beta$ plaques (depicted in green). Column marked "merged" depicts a merged dual color depiction of the corresponding tomato lectin and $A \beta$ immunostaining. Scale Bar, $25 \mu \mathrm{m}$. ( $n=3 /$ group). G-J. Two representative sections from the hippocampus of EGFP $(\mathrm{G}-\mathrm{H})$ or mTNFa expressing mice (I-J) from 5.5 month old TgCRND8 mice depicting increased MHCII stained cells with the morphology of peripheral monocytes around cored plaques in MTNF $\alpha$ expressing animals. The sections have been counterstained with hematoxylin and Congo Red. Scale Bar, $25 \mu \mathrm{m}$. ( $n=5$ /group). K. The number of MHCIl immunopositive cells in the immediate proximity of Congophilic $A \beta$ cored plaques were quantified by averaging from at least ten individual plaques from each sample. $\left({ }^{*} p<0.05 ; t\right.$ test; $n=5 /$ group).

$\mathrm{A} \beta$ aggregates themselves impair glial function. Thus, as $A \beta$ accumulates, glia-mediated clearance of $A \beta$ aggregates decreases and such an effect could account for an apparent age-related effect in certain models. As shown here, in some circumstances it appears possible to modulate innate immune cell effector function in a manner that limits $A \beta$ accumulation. Whether this modulation can be done safely remains an open question; balancing potential beneficial effects of innate immune cell activation in $\mathrm{AD}$ with potential neurotoxic consequences remains a formidable obstacle to development of therapies that involve manipulation of innate immunity. 


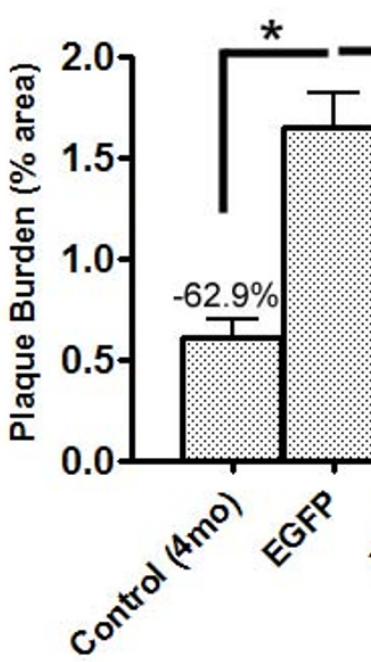

Figure 6 Comparative analysis of $A \beta$ plaque burden in TgCRND8 mice following acute hippocampal expression of pro-inflammatory cytokines. 4 month old TgCRND8 mice were stereotaxically injected in the hippocampus with either rAAV2/1-IL-6, rAAV2/1-mIFN $\gamma$, rAAV2/1-mTNF $\alpha$ or rAAV2/1-EGFP and sacrificed after 6 weeks. Quantification of forebrain A $\beta$ plaque burdens in 5.5 month old mice compared to unmanipulated 4 month old TgCRND8 mice is shown. ${ }^{*} p$ and ${ }^{*} p=0.0011$; one way ANOVA; $n=5-6 /$ group).

\section{Additional material}

Additional file 1: Figure S1: AAV2/1 mediated expression of transgene in mice hippocampus. A-D. AAV2/1-EGFP was

stereotactically injected into the hippocampus of 4 month old TgCRND8 mice and analyzed after 6 weeks. Representative images of EGFP immunoreactivity on paraffin embedded whole brain sections (A, B) and the hippocampus (C, D) of EGFP injected or uninjected mice are shown. Scale Bar, $600 \mu \mathrm{m}(\mathrm{A}, \mathrm{B})$ and $25 \mu \mathrm{m}(\mathrm{C}, \mathrm{D})$. ( $n=6 /$ group). E. Expression of mTNF $\alpha$ was determined in 5.5 month old mTNF $\alpha$ expressing TgCRND8 mice compared to EGFP expressing age-matched transgenic controls using real time Q-PCR. Relative quantitation of mRNA transcript levels was performed using the comparative cycle threshold method. $\beta$-actin was used to normalize expression levels from the samples. Data, expressed as relative units of mRNA expression, represents averaged fold change values obtained from $M T N F \alpha$ expressing mice, relative to averaged values obtained from EGFP expressing mice. ( $n=3$ /group, $\left.{ }^{*} p<0.05\right)$.

Additional file 2: Figure S2. No significant changes in hippocampal CA neurons following acute hippocampal expression of rAAV2/1mTNF $\alpha$. Quantification of cell count of the hippocampal pyramidal cells (CA1, CA2 and CA3) in TgCRND8 mice expressing mTNF $\alpha$ compared to controls is depicted. Data from three sections from each sample, spaced $30 \mu \mathrm{m}$ apart, were averaged using the Aperio "nuclear quantification" program for the final output. ( $n=4 /$ group).

Additional file 3: Figure S3. No evidence of T cell accumulation around hippocampal A $\beta$ plaques in rAAV2/1-mTNF $\alpha$ expressing animals. Representative sections depicting CD3 immunostaining in tonsil (A) and 5.5 month old TgCRND8 mice injected with rAAV2/1-mTNFa in the hippocampus at 4 months of age (B). There is copious amounts of CD3 immunostained T cells in the tonsil ( $A$ and inset). Though we noticed some CD3 immunopositivity in the ventricles of 5.5 month old mTNF $\alpha$ expressing TgCRND8 mice (B and 2), we did not observe any T cell staining around $A \beta$ plaques (asterisk "*" mark) in the hippocampus of and $25 \mu \mathrm{m}(1,2)$. ( $n=4$ /group).

\section{Abbreviations}

(AAV): Adeno-associated virus; (AD): Alzheimer's disease; $(A B)$ : Amyloid $\beta$; (APP): Amyloid $\beta$ precursor protein; (CTF): C-terminal fragment; (EGFP): Enhanced green fluorescent protein; (GFAP): Glial fibrillary acidic protein; (IACUC): Institutional animal care and use committee; (IL-1 $\beta)$ :Interleukin-1 $\beta$; (IL-6):Interleukin-6; 1 (Iba-1): Ionized calcium binding adaptor protein; (MHC II): Major histocompatibility complex II; (mTNFa): murine Tumor necrosis factor $a ;(3 \times T g-A D)$ : triple transgenic mice.

\section{Acknowledgements}

This work was supported by Mayo Clinic (TEG), National Institutes of Health/ National Institute on Aging Grants (RO1AG18454, RO1AG29886, P01AG25531; TEG) and American Health Assistance Foundation Grant A2009061 (PD).

\section{Author details}

${ }^{1}$ Center for Translational Research in Neurodegenerative Disease, College of Medicine, University of Florida, 1275 Center Drive, Gainesville, PO Box \#100159, FL-32610, USA. ${ }^{2}$ Department of Neuroscience, Mayo Clinic College of Medicine, 4500 San Pablo Rd S, Jacksonville, FL-32224, USA.

\section{Authors' contributions}

PC conducted the experiments and wrote the initial manuscript; $A B$ performed amyloid burden analysis; CC-D prepared AAV2/1 viruses and quantitative PCR; PC, PD and TEG conceived the study and its design. PD and TG supervised the project and edited the manuscript preparation. All authors have read and approved the manuscript.

\section{Competing interests}

The authors declare that they have no competing interests.

Received: 5 October 2010 Accepted: 16 February 2011 Published: 16 February 2011

\section{References}

1. Glass CK, Saijo K, Winner B, Marchetto MC, Gage FH: Mechanisms underlying inflammation in neurodegeneration. Cell 2010, 140:918-934.

2. Chakrabarty P, Ceballos-Diaz C, Beccard A, Janus C, Dickson D, Golde TE, Das P: IFN-gamma promotes complement expression and attenuates amyloid plaque deposition in amyloid beta precursor protein transgenic mice. J Immunol 2010, 184:5333-5343.

3. Chakrabarty P, Jansen-West K, Beccard A, Ceballos-Diaz C, Levites Y, Verbeeck C, Zubair AC, Dickson D, Golde TE, Das P: Massive gliosis induced by interleukin- 6 suppresses $A\{$ beta\} deposition in vivo: evidence against inflammation as a driving force for amyloid deposition. Faseb J 2009, 24:548-559.

4. Shaftel SS, Kyrkanides S, Olschowka JA, Miller JN, Johnson RE, O'Banion MK: Sustained hippocampal IL-1 beta overexpression mediates chronic neuroinflammation and ameliorates Alzheimer plaque pathology. I Clin Invest 2007, 117:1595-1604

5. Boissonneault V, Filali M, Lessard M, Relton J, Wong G, Rivest S: Powerful beneficial effects of macrophage colony-stimulating factor on betaamyloid deposition and cognitive impairment in Alzheimer's disease. Brain 2009, 132:1078-1092.

6. Richard KL, Filali M, Prefontaine P, Rivest S: Toll-like receptor 2 acts as a natural innate immune receptor to clear amyloid beta 1-42 and delay the cognitive decline in a mouse model of Alzheimer's disease. J Neurosci 2008, 28:5784-5793.

7. Town T, Laouar Y, Pittenger C, Mori T, Szekely CA, Tan J, Duman RS, Flavell RA: Blocking TGF-beta-Smad2/3 innate immune signaling mitigates Alzheimer-like pathology. Nat Med 2008, 14:681-687.

8. El Khoury J, Toft M, Hickman SE, Means TK, Terada K, Geula C, Luster AD: Ccr2 deficiency impairs microglial accumulation and accelerates progression of Alzheimer-like disease. Nat Med 2007, 13:432-438. 
9. Wajant $\mathrm{H}$, Pfizenmaier K, Scheurich P: Tumor necrosis factor signaling. Cell Death Differ 2003, 10:45-65.

10. Covey WC, Ignatowski TA, Renauld AE, Knight PR, Nader ND, Spengler RN: Expression of neuron-associated tumor necrosis factor alpha in the brain is increased during persistent pain. Reg Anesth Pain Med 2002, 27:357-366.

11. Park KM, Bowers WJ: Tumor necrosis factor-alpha mediated signaling in neuronal homeostasis and dysfunction. Cell Signal 2010, 22:977-983.

12. Tan ZS, Beiser AS, Vasan RS, Roubenoff R, Dinarello CA, Harris TB, Benjamin EJ, Au R, Kiel DP, Wolf PA, Seshadri S: Inflammatory markers and the risk of Alzheimer disease: the Framingham Study. Neurology 2007 68:1902-1908.

13. Dickson DW: The pathogenesis of senile plaques. Journal of Neuropathology \& Experimental Neurology 1997, 56:321-339.

14. Paganelli R, Di lorio A, Patricelli L, Ripani F, Sparvieri E, Faricelli R, larlori C, Porreca E, Di Gioacchino M, Abate G: Proinflammatory cytokines in sera of elderly patients with dementia: levels in vascular injury are higher than those of mild-moderate Alzheimer's disease patients. Exp Gerontol 2002, 37:257-263.

15. Bongioanni P, Romano MR, Sposito R, Castagna M, Boccardi B, Borgna M: Tcell tumour necrosis factor-alpha receptor binding in demented patients. J Neurol 1997, 244:418-425.

16. Collins JS, Perry RT, Watson B Jr, Harrell LE, Acton RT, Blacker D, Albert MS, Tanzi RE, Bassett SS, McInnis MG, et al: Association of a haplotype for tumor necrosis factor in siblings with late-onset Alzheimer disease: the NIMH Alzheimer Disease Genetics Initiative. Am J Med Genet 2000, 96:823-830.

17. Perry RT, Collins JS, Wiener H, Acton R, Go RC: The role of TNF and its receptors in Alzheimer's disease. Neurobiol Aging 2001, 22:873-883.

18. He P, Zhong Z, Lindholm K, Berning L, Lee W, Lemere C, Staufenbiel M, $L i R$, Shen Y: Deletion of tumor necrosis factor death receptor inhibits amyloid beta generation and prevents learning and memory deficits in Alzheimer's mice. J Cell Biol 2007, 178:829-841.

19. MCAlpine FE, Lee JK, Harms AS, Ruhn KA, Blurton-Jones M, Hong J, Das P, Golde TE, LaFerla FM, Oddo $S$, et al: Inhibition of soluble TNF signaling in a mouse model of Alzheimer's disease prevents pre-plaque amyloidassociated neuropathology. Neurobiol Dis 2009, 34:163-177.

20. Janelsins MC, Mastrangelo MA, Oddo S, LaFerla FM, Federoff HJ, Bowers WJ: Early correlation of microglial activation with enhanced tumor necrosis factor-alpha and monocyte chemoattractant protein-1 expression specifically within the entorhinal cortex of triple transgenic Alzheimer's disease mice. J Neuroinflammation 2005, 2:23.

21. Janelsins MC, Mastrangelo MA, Park KM, Sudol KL, Narrow WC, Oddo S, Laferla FM, Callahan LM, Federoff HJ, Bowers WJ: Chronic Neuron-Specific Tumor Necrosis Factor-Alpha Expression Enhances the Local Inflammatory Environment Ultimately Leading to Neuronal Death in $3 \times$ Tg-AD Mice. Am J Pathol 2008, 173:1768-1782.

22. Chishti MA, Yang DS, Janus C, Phinney AL, Horne P, Pearson J, Strome R, Zuker N, Loukides J, French J, et al: Early-onset amyloid deposition and cognitive deficits in transgenic mice expressing a double mutant form of amyloid precursor protein 695. J Biol Chem 2001, 276:21562-21570.

23. Kim J, Miller VM, Levites Y, West KJ, Zwizinski CW, Moore BD, Troendle FJ, Bann M, Verbeeck C, Price RW, et al: BRI2 (ITM2b) inhibits Abeta deposition in vivo. J Neurosci 2008, 28:6030-6036.

24. Tartaglia LA, Pennica D, Goeddel DV: Ligand passing: the $75-k D a$ tumor necrosis factor (TNF) receptor recruits TNF for signaling by the $55-\mathrm{kDa}$ TNF receptor. J Biol Chem 1993, 268:18542-18548.

25. Griffin WS, Sheng JG, Royston MC, Gentleman SM, McKenzie JE, Graham DI, Roberts GW, Mrak RE: Glial-neuronal interactions in Alzheimer's disease: the potential role of a 'cytokine cycle' in disease progression. Brain Pathol 1998, 8:65-72.

26. Bard F, Cannon C, Barbour R, Burke RL, Games D, Grajeda H, Guido T, Hu K, Huang J, Johnson-Wood K, et al: Peripherally administered antibodies against amyloid beta-peptide enter the central nervous system and reduce pathology in a mouse model of Alzheimer disease. Nat Med 2000, 6:916-919.

27. Monsonego A, Imitola J, Petrovic S, Zota V, Nemirovsky A, Baron R, Fisher $\mathrm{Y}$, Owens T, Weiner HL: Abeta-induced meningoencephalitis is IFN-gammadependent and is associated with T cell-dependent clearance of Abeta in a mouse model of Alzheimer's disease. Proc Natl Acad Sci USA 2006, 103:5048-5053.
28. Rogers J, Strohmeyer R, Kovelowski CJ, Li R: Microglia and inflammatory mechanisms in the clearance of amyloid beta peptide. Glia 2002, 40:260-269.

29. Mandrekar S, Jiang Q, Lee CY, Koenigsknecht-Talboo J, Holtzman DM, Landreth GE: Microglia mediate the clearance of soluble Abeta through fluid phase macropinocytosis. J Neurosci 2009, 29:4252-4262.

30. Majumdar A, Cruz D, Asamoah N, Buxbaum A, Sohar I, Lobel P, Maxfield FR: Activation of microglia acidifies lysosomes and leads to degradation of Alzheimer amyloid fibrils. Mol Biol Cell 2007, 18:1490-1496.

31. Lamb BT, Sisodia SS, Lawler AM, Slunt HH, Kitt CA, Kearns WG, Pearson PL, Price DL, Gearhart JD: Introduction and expression of the 400 kilobase precursor amyloid protein gene in transgenic mice. Nature genetics 1993, 5:22-29.

32. Njie EG, Boelen E, Stassen FR, Steinbusch HW, Borchelt DR, Streit WJ: Ex vivo cultures of microglia from young and aged rodent brain reveal age-related changes in microglial function. Neurobiol Aging 2010.

33. Dickson DW: Microglia in Alzheimer's disease and transgenic models. How close the fit? Am J Pathol 1999, 154:1627-1631.

doi:10.1186/1750-1326-6-16

Cite this article as: Chakrabarty et al:: Hippocampal expression of murine TNF $\alpha$ results in attenuation of amyloid deposition in vivo. Molecular Neurodegeneration 2011 6:16.

\section{Submit your next manuscript to BioMed Central and take full advantage of:}

- Convenient online submission

- Thorough peer review

- No space constraints or color figure charges

- Immediate publication on acceptance

- Inclusion in PubMed, CAS, Scopus and Google Scholar

- Research which is freely available for redistribution

Submit your manuscript at www.biomedcentral.com/submit
C Biomed Central 